\title{
Risk factors for death by acute ischaemic stroke in patients from West-Pomerania, Poland
}

\author{
Paweł Wańkowicz, Monika Gołąb-Janowska, Przemysław Nowacki \\ Department of Neurology, Pomeranian Medical University, Szczecin, Poland
}

\begin{abstract}
:
Aim and clinical rationale for study. In Poland, it is widely believed that the outlook for ischaemic stroke patients is gradually improving due to the development of a network of stroke wards and other dedicated hospital units throughout the country. However, a study by Shah et al., reporting a significant increase in mortality from ischaemic stroke in several European countries including Poland, contradicts this belief. Therefore, the aim of this study was to determine the risk factors for death in patients with recent ischaemic stroke among a population of patients from Western Pomerania, a region in north-western Poland.

Materials and methods. This retrospective study involved 2,374 patients with recent ischaemic stroke. Mortality was defined as death within 30 days of admission to hospital. Patients who died in hospital during this period were defined as deceased, while those who survived beyond this time were classified as alive.

Results. We found that compared to ischaemic stroke patients who survived, the group of ischaemic stroke patients who died included a higher number of patients who smoked cigarettes $(O R=6.08$ in univariable model; $O R=6.22$ in adjusted model), had hypertension $(O R=2.57 ; O R=1.85)$, had a history of previous stroke $(O R=2.63 ; O R=2.14)$, had coronary heart disease $(O R=1.78 ; O R=1.36)$, and were older $(O R=1.06 ; O R=1.05)$. For all these factors, $p$-value was lower than 0.001 . Females had a higher risk of death $(\mathrm{OR}=1.48, \mathrm{p}<0.001 ; \mathrm{OR}=1.35, \mathrm{p}=0.01)$. For dyslipidemia, only univariable model was statistically significant $(O R=1.38, p<0.001)$.

Conclusion and clinical implications. Older age, female sex, dyslipidemia, hypertension, coronary heart disease, and smoking are not only recognised risk factors for ischaemic stroke, but also risk factors associated with an unfavourable prognosis following stroke.
\end{abstract}

Key words: ischaemic stroke, risk factors, death, Poland

(Neurol Neurochir Pol 2020; 54 (2): 150-155)

\section{Introduction}

Ischaemic stroke (IS) is one of the most common causes of death and long-term disability. Due to the need for patients to undergo long-term rehabilitation and care, it is also one of the most expensive diseases to treat [1]. Over the last decade, there has been a marked decline in mortality resulting from IS throughout much of Europe, reflecting positive trends in the prevention of cardiovascular disease as a whole. These trends result from early implementation of primary prevention strategies and improved treatment and care, leading to a reduction in mortality among IS patients. Despite these changes, stroke remains the second leading cause of death in Europe after ischaemic heart disease, responsible for $9 \%$ of deaths in men and $13 \%$ in women [2].

\section{Clinical rationale for this study}

In Poland, it is widely believed that the outlook for IS patients is gradually improving due to the development of a network of stroke wards and other dedicated hospital units throughout the country, which is confirmed by the GBD 2016 Stroke Collaborators study [3]. However, a study by Shah et al., reporting a significant increase in mortality from IS in 
both men and women in several European countries including Poland, contradicts this belief [4]. Therefore, the aim of this study was to determine the risk factors for death in patients with recent IS among a population of patients from Western Pomerania, a region in north-western Poland.

\section{Materials and methods}

This retrospective study involved 2,374 patients with recent IS, hospitalised at the Department of Neurology, Pomeranian Medical University in Szczecin between December 2014 and January 2019. A standardised data sheet was used to record gender, age, presence of hypertension, diabetes, dyslipidemia, history of ischaemic stroke, coronary heart disease, significant stenosis of the internal carotid artery, and tobacco smoking. Mortality was defined as death within 30 days of admission to hospital. Patients who died in hospital during this period were defined as 'deceased', while those who survived beyond this time were classified as 'alive'. In our study, 1,679 patients (71\%) survived this period, while 695 died (29\%).

IS was defined as sudden onset of a focal neurological deficit, as determined by brain computed tomography and/ or magnetic resonance imaging. Diabetes mellitus was defined by elevated fasting blood glucose greater than $126 \mathrm{mg} /$ $\mathrm{dl}$ in at least two tests or a fasting blood glucose greater than $200 \mathrm{mg} / \mathrm{dl}$ at any time during the day before a stroke episode [5]. Dyslipidemia was defined as the combination of serum cholesterol concentration $>190 \mathrm{mg} / \mathrm{dl}$, low-density cholesterol $>115 \mathrm{mg} / \mathrm{dl}$, serum triglyceride concentration $>150 \mathrm{mg} /$ $\mathrm{dl}$, and high-density cholesterol $<40 \mathrm{mg} / \mathrm{dl}$ in males and $<45 \mathrm{mg} / \mathrm{dl}$ in females before a stroke episode [6]. Hypertension was diagnosed when blood pressure was greater than $140 / 90 \mathrm{mmHg}$ in repeated tests before a stroke episode [7]. Coronary heart disease was determined by a previous history of angina pectoris, myocardial infarction or coronary artery disease without infarction. Smokers were defined as people who had smoked one or more cigarettes in their lifetime. Previous stroke was considered to be present if the medical charts included a stroke diagnosis. Based on examination USG or angio-CT or angio-MR, significant stenosis of the internal carotid artery was defined as stenosis of $70 \%$ or higher $[8,9]$. Due to the fact that the above-mentioned risk factors are also recognised risk factors for atrial fibrillation, atrial fibrillation was not taken into further analysis. The Pomeranian Medical University Ethics Committee approved the study protocol (KB-0012/178/07/19).

\section{Statistics}

To compare the characteristics of IS in patients who survived to those of the deceased, the Mann-Whitney Test (quantitative data) and the Fisher Exact Test (qualitative data) were used. In addition, univariable and multivariable logistic regression models were calculated for assessing the odds ratios of chosen risk factors of death incidence among IS patients. Statistical significance was set at $\mathrm{p}<0.01$. All statistical analyses were performed using ' $R$ ' programming environment.

\section{Results}

\section{Analysis of risk factors for death in ischaemic stroke patients}

Cigarette smoking, hypertension, older age, female gender, dyslipidemia, coronary heart disease, and history of ischaemic stroke were more common in IS patients who died than in surviving IS patients. A case comparison is presented in Table 1.

Compared to ischaemic stroke patients who survived, the group of ischaemic stroke patients who died included a higher number who smoked cigarettes $(\mathrm{OR}=6.08$ in univariable model; $\mathrm{OR}=6.22$ in adjusted model), had hypertension $(\mathrm{OR}=2.57 ; \mathrm{OR}=1.85)$, had a history of a previous stroke $(\mathrm{OR}=2.63 ; \mathrm{OR}=2.14)$, had coronary heart disease $(\mathrm{OR}=1.78$; $\mathrm{OR}=1.36)$, and were older $(\mathrm{OR}=1.06 ; \mathrm{OR}=1.05)$. For all these factors, $\mathrm{p}$-value was lower than 0.001 . Also, females had a higher risk of death $(\mathrm{OR}=1.48, \mathrm{p}<0.001$; $\mathrm{OR}=1.35$, $\mathrm{p}=0.01)$. For dyslipidemia, only univariable model was statistically significant $(\mathrm{OR}=1.38, \mathrm{p}<0.001)(\mathrm{Tab} .2)$.

\section{Discussion}

Hypertension is not only one of the most frequent causes of stroke, but also increases the risk of morbidity and mortality from cardiovascular causes [10]. Treatment of hypertension reduces the risk of general mortality, and the reduction of risk depends on the degree of pressure reduction. Thus, lowering high blood pressure has been proposed as a major factor for the reduction in stroke death rates during the 21 st century [11]. In a meta-analysis involving one million adult patients, the researchers found that between the ages of 40-69 years, each incremental rise of $20 \mathrm{mmHg}$ systolic blood pressure and $10 \mathrm{mmHg}$ diastolic blood pressure, beginning with systolic blood pressure of $115 \mathrm{mmHg}$ and diastolic blood pressure of $75 \mathrm{mmHg}$, was associated with a two-fold increase in death rates from stroke [12]. Other clinical analysis have demonstrated that control of isolated systolic blood pressure reduces total and stroke mortality $[13,14]$. Reductions of $4.7 \mathrm{mmHg}$ blood pressure reduced stroke mortality by $17.6 \%$ [15]. Our study confirms that arterial hypertension in ischaemic stroke patients is a prognostic factor, as it increases the risk of death by a factor of 2.5 .

The impact of cigarette smoking on stroke risk and mortality is also well established [16]. Estimates of the risk of stroke related to smoking vs. non-smoking vary according to epidemiological studies and stroke type. However, there is a correlation between the number of cigarettes smoked and the risk of ischaemic stroke. Likewise, cessation of smoking reduces the risk of stroke [17]. In spite of this, there are discrepancies in the research as to whether smoking can serve as a prognostic 
Table 1. Characteristics of patients with ischaemic stroke. Deceased patients vs. Alive patients

\begin{tabular}{|c|c|c|c|}
\hline & $\begin{array}{c}\text { Alive } \\
\mathrm{n}=1,679\end{array}$ & $\begin{array}{c}\text { Deceased } \\
n=695\end{array}$ & p value \\
\hline \multirow[t]{2}{*}{ Age } & \multicolumn{2}{|c|}{ Mean/Median/SD } & \\
\hline & $68.15 / 67.0 / 11.65$ & $75.5 / 78.0 / 10.79$ & $<0.001$ \\
\hline \multicolumn{4}{|l|}{ Sex } \\
\hline $\mathrm{F}$ & $873(36.8 \%)$ & $428(18.0 \%)$ & \multirow[t]{2}{*}{$<0.001$} \\
\hline M & 806 (34.0\%) & 267 (11.2\%) & \\
\hline \multicolumn{4}{|c|}{ Diabetes mellitus } \\
\hline no & $1146(48.3 \%)$ & $458(19.3 \%)$ & \multirow[t]{2}{*}{0.27} \\
\hline yes & $533(22.5 \%)$ & $237(10.0 \%)$ & \\
\hline \multicolumn{4}{|c|}{ Dyslipidemia } \\
\hline no & $1095(46.1 \%)$ & $400(16.8 \%)$ & \multirow[t]{2}{*}{$<0.001$} \\
\hline yes & $584(24.6 \%)$ & $295(12.4 \%)$ & \\
\hline \multicolumn{4}{|c|}{ Hypertension } \\
\hline no & $490(20.6 \%)$ & $96(4.0 \%)$ & \multirow[t]{2}{*}{$<0.001$} \\
\hline yes & $1189(50.1 \%)$ & $599(25.2 \%)$ & \\
\hline \multicolumn{4}{|c|}{ ICA significant stenosis/occlusion } \\
\hline no & $1425(60.0 \%)$ & $605(25.5 \%)$ & \multirow[t]{2}{*}{0.18} \\
\hline yes & $254(10.7 \%)$ & $90(3.8 \%)$ & \\
\hline \multicolumn{4}{|c|}{ Coronary heart disease } \\
\hline no & $944(39.8 \%)$ & $291(12.3 \%)$ & \multirow[t]{2}{*}{$<0.001$} \\
\hline yes & 735 (31.0\%) & $404(17.0 \%)$ & \\
\hline \multicolumn{4}{|c|}{ Smoking } \\
\hline no & $1,356(57.1 \%)$ & $284(12.0 \%)$ & \multirow[t]{2}{*}{$<0.001$} \\
\hline yes & $323(13.6 \%)$ & 411 (17.3\%) & \\
\hline \multicolumn{4}{|c|}{ Previous stroke } \\
\hline no & $1,341(56.5 \%)$ & $418(17.6 \%)$ & \multirow[t]{2}{*}{$<0.001$} \\
\hline yes & $338(14.2 \%)$ & $277(11.7 \%)$ & \\
\hline
\end{tabular}

factor. In our analysis, cigarette smoking was associated with a six-fold increase in the risk of death in ischaemic stroke patients. In a study conducted by Kuller et al., among the 361,662 men analysed, the risk of mortality from ischaemic stroke among smokers was 2.5 times greater than among those who had never smoked [18]. In another study, the risk of stroke mortality in current smokers compared to never-smokers was 1.7 times greater in men and 2.2 times greater in women [19]. These observations seem to be confirmed by Towfighi et al., who in their work showed that among ischaemic stroke patients, abstinence from smoking was associated with lower overall mortality [20].

At least $25 \%$ of ischaemic stroke patients experience a recurrent stroke within five years after the first stroke. Very often, recurrent strokes are characterised by poor prognosis and end in death within the first month after its occurrence in $25 \%$ of patients [21]. The risk of recurrence is the highest in the first six months after the first vascular episode. Within 10 years, it is six times higher than the risk of first stroke in the general population of the same age and sex [22]. Recurrent strokes are accompanied by an increased risk of disability and are associated with higher costs compared to the first vascular episode. Numerous epidemiological studies have shown that early mortality is more often associated with recurrent stroke, whereas later mortality is usually associated with cardiovascular causes [23-26]. In our analysis, recurrent ischaemic stroke was associated with a doubled risk of death.

The relationship between ischaemic heart disease and increased mortality in cerebral ischaemic stroke patients has been demonstrated in many studies $[27,28]$. In our study, a history of ischaemic heart disease in patients with cerebral ischaemic stroke was associated with a 1.7 times higher risk of death compared to patients without ischaemic heart disease.

In most age groups, the incidence rate of stroke is higher in men, although after the age of 85 it is higher in women. As the population ages, the proportion of stroke incidence between men and women also shifts. It is predicted that by $2050,60 \%$ of stroke patients will be women. Most researchers agree that 
Table 2. Analysis of risk factors of death in patients with ischaemic stroke (univariable and multivariable logistic regression models)

\begin{tabular}{|c|c|c|c|c|c|c|c|}
\hline \multirow[t]{2}{*}{ Factors } & & \multicolumn{3}{|c|}{ Univariable Logistic Regression Models } & \multicolumn{3}{|c|}{ Multivariable Logistic Regression Model * } \\
\hline & & OR & Cl & $P$-value & OR & Cl & $P$-value \\
\hline \multicolumn{8}{|l|}{ Age } \\
\hline & & 1.06 & $1.05-1.07$ & $<0.001$ & 1.05 & $1.04-1.06$ & $<0.001$ \\
\hline \multicolumn{8}{|l|}{ Hypertension } \\
\hline & yes & 2.57 & $2.03-3.28$ & $<0.001$ & 1.85 & $1.42-2.44$ & $<0.001$ \\
\hline & no & 1.0 & - & - & 1.0 & - & - \\
\hline \multicolumn{8}{|l|}{ Smoking } \\
\hline & yes & 6.08 & $5.01-7.38$ & $<0.001$ & 6.22 & $5.02-7.73$ & $<0.001$ \\
\hline & no & 1.0 & - & - & 1.0 & - & - \\
\hline \multicolumn{8}{|l|}{ Previous stroke } \\
\hline & yes & 2.63 & $2.17-3.19$ & $<0.001$ & 2.14 & $1.71-2.68$ & $<0.001$ \\
\hline & no & 1.0 & - & - & 1.0 & - & - \\
\hline \multicolumn{8}{|l|}{ Dyslipidemia } \\
\hline & yes & 1.38 & $1.15-1.66$ & $<0.001$ & 0.85 & $0.69-1.06$ & 0.15 \\
\hline & no & 1.0 & - & - & 1.0 & - & - \\
\hline \multicolumn{8}{|c|}{ ICA significant stenosis/occlusion } \\
\hline & yes & 0.83 & $0.64-1.08$ & 0.17 & 0.73 & $0.54-0.98$ & 0.04 \\
\hline & no & 1.0 & - & - & 1.0 & - & - \\
\hline \multicolumn{8}{|l|}{ Sex } \\
\hline & $\mathrm{M}$ & 1.0 & - & - & 1.0 & - & - \\
\hline & $\mathrm{F}$ & 1.48 & $1.24-1.77$ & $<0.001$ & 1.35 & $1.09-1.68$ & 0.01 \\
\hline \multicolumn{8}{|l|}{ Diabetes mellitus } \\
\hline & yes & 1.11 & $0.92-1.34$ & 0.26 & 0.96 & $0.77-1.19$ & 0.7 \\
\hline & no & 1.0 & - & - & 1.0 & - & - \\
\hline \multicolumn{8}{|l|}{ Coronary heart disease } \\
\hline & yes & 1.78 & $1.49-2.13$ & $<0.001$ & 1.36 & $1.1-1.68$ & $<0.001$ \\
\hline & no & 1.0 & - & - & 1.0 & - & - \\
\hline
\end{tabular}

Status $=1-$ deceased, status $=0-$ alive

*Fully adjusted model; Independent variables: Age; Hypertension (yes/no); Smoking (yes/no); Previous Stroke (yes/no); Dyslipidemia (yes/no); ICA significant stenosis/occlusion (yes/no); Sex (M/F); Diabetes mellitus (yes/no); Coronary heart disease (yes/no)

disability and mortality rates are higher in women due to their older age at the time of stroke. The increased mortality of female patients is largely due to the initial differences between men and women, i.e. the distribution of coexisting diseases, the severity of stroke, and age. In this study, both female sex and older age were unfavourable factors in determining prognosis. Many studies have also shown that older age has a negative impact on stroke morbidity, short and long-term outcomes, and mortality [29-31].

The relationship between dyslipidemia and ischaemic stroke is a complex issue in light of current research. In some studies, dyslipidemia has been associated with a worse prognosis, while other reports refute this [32-37]. Also, in our study, univariable analyses showed that the concurrence of dyslipidemia in ischaemic stroke patients was associated with higher mortality; however, this was not confirmed by multivariable analyses, which probably results from heterogeneity of strokes.

It is worth mentioning that our study had several limitations. This was a single centre retrospective study, with a limited number of IS patients. We selected only the most common risk factors of IS. Further prospective studies with a larger sample size are needed.

\section{Clinical implications/future directions}

Older age, female sex, dyslipidemia, hypertension, coronary heart disease, and smoking are not only recognised risk 
factors for ischaemic stroke, but also risk factors associated with an unfavourable prognosis following stroke. Our research indicates the need for particularly thorough and systematic care of patients who exhibit the aforementioned factors. The results indicate the significance of lifestyle modification, including cessation of smoking, dietary adjustment, and, if possible, increased physical activity among this group of patients.

Acknowledgements: Not applicable

Conflicts of interest: None

Funding: This research received no grant

\section{References}

1. Xu XM, Vestesson E, Paley L, et al. The economic burden of stroke care in England, Wales and Northern Ireland: Using a national stroke register to estimate and report patient-level health economic outcomes in stroke. Eur Stroke J. 2018; 3(1): 82-91, doi: 10.1177/2396987317746516, indexed in Pubmed: 29900412.

2. Timmis A, Townsend N, Gale C, et al. ESC Scientific Document Group. European Society of Cardiology: Cardiovascular Disease Statistics 2017. Eur Heart J. 2018; 39(7): 508-579, doi: 10.1093/eurheartj/ ehx628, indexed in Pubmed: 29190377.

3. Wallin M, Culpepper W, Nichols E, et al. Global, regional, and national burden of multiple sclerosis 1990-2016: a systematic analysis for the Global Burden of Disease Study 2016. The Lancet Neurology. 2019; 18(3): 269-285, doi: 10.1016/s1474-4422(18)30443-5.

4. Shah R, Wilkins E, Nichols M, et al. Epidemiology report: trends in sex-specific cerebrovascular disease mortality in Europe based on WHO mortality data. Eur Heart J. 2019; 40(9): 755-764, doi: 10.1093/ eurheartj/ehy378, indexed in Pubmed: 30124820.

5. Tahrani AA, Bailey CJ, Del Prato S, et al. Management of type 2 diabetes: new and future developments in treatment. Lancet. 2011; 378(9786): 182-197, doi: 10.1016/S0140-6736(11)60207-9, indexed in Pubmed: 21705062.

6. Grundy S, Cleeman J, Merz C, et al. Implications of Recent Clinical Trials for the National Cholesterol Education Program Adult Treatment Panel III Guidelines. Arteriosclerosis, Thrombosis, and Vascular Biology. 2004; 24(8), doi: 10.1161/01.atv.0000133317.49796.0e.

7. Mansia G, De Backer G, Dominiczak A, et al. European Society of Hypertension, European Society of Cardiology, Management of Arterial Hypertension of the European Society of Hypertension, European Society of Cardiology. 2007 Guidelines for the management of arterial hypertension: The Task Force for the Management of Arterial Hypertension of the European Society of Hypertension (ESH) and of the European Society of Cardiology (ESC). Eur Heart J. 2007; 28(12): 1462-1536, doi: 10.1093/eurheartj/ehm236, indexed in Pubmed: 17562668.

8. Inzitari D, Eliasziw $M$, Gates $P$, et al. The causes and risk of stroke in patients with asymptomatic internal-carotid-artery stenosis. North American Symptomatic Carotid Endarterectomy Trial Collaborators. N Engl J Med. 2000; 342(23): 1693-1700, doi: 10.1056/ NEJM200006083422302, indexed in Pubmed: 10841871.

9. Halliday A, Harrison M, Hayter E, et al. Asymptomatic Carotid Surgery Trial (ACST) Collaborative Group. 10-year stroke prevention after successful carotid endarterectomy for asymptomatic stenosis (ACST1): a multicentre randomised trial. Lancet. 2010; 376(9746): 10741084, doi: 10.1016/S0140-6736(10)61197-X, indexed in Pubmed: 20870099.
10. Williams B, Mancia G, Spiering W, et al. List of authors/Task Force members:, Authors/Task Force Members:. 2018 ESC/ESH Guidelines for the management of arterial hypertension: The Task Force for the management of arterial hypertension of the European Society of Cardiology and the European Society of Hypertension: The Task Force for the management of arterial hypertension of the European Society of Cardiology and the European Society of Hypertension. J Hypertens. 2018; 36(10): 1953-2041, doi: 10.1097/HJH.0000000000001940, indexed in Pubmed: 30234752.

11. Kuller LH. Epidemiology and prevention of stroke, now and in the future. Epidemiol Rev. 2000; 22(1): 14-17, doi: 10.1093/oxfordjournals. epirev.a018011, indexed in Pubmed: 10939002.

12. Lewington S, Clarke R, Qizilbash N, et al. Prospective Studies Collaboration. Age-specific relevance of usual blood pressure to vascular mortality: a meta-analysis of individual data for one million adults in 61 prospective studies. Lancet. 2002; 360(9349): 1903-1913, doi: 10.1016/s0140-6736(02)11911-8, indexed in Pubmed: 12493255.

13. Prevention of stroke by antihypertensive drug treatment in older persons with isolated systolic hypertension. Final results of the Systolic Hypertension in the Elderly Program (SHEP). SHEP Cooperative Research Group. JAMA. 1991; 265(24): 3255-3264, indexed in Pubmed: 2046107.

14. Staessen JA, Thijs L, Fagard R, et al. Predicting cardiovascular risk using conventional vs ambulatory blood pressure in older patients with systolic hypertension. Systolic Hypertension in Europe Trial Investigators. JAMA. 1999; 282(6): 539-546, doi: 10.1001/jama.282.6.539, indexed in Pubmed: 10450715.

15. Lackland DT, Egan BM, Mountford WK, et al. Thirty-year Survival for Black and White Hypertensive Individuals in the Evans County Heart Study and the Hypertension Detection and Follow-up Program. J Am Soc Hypertens. 2008; 2(6): 448-454, doi: 10.1016/j. jash.2008.05.007, indexed in Pubmed: 19169432.

16. Shinton R, Beevers G. Meta-analysis of relation between cigarette smoking and stroke. BMJ. 1989; 298(6676): 789-794, doi: 10.1136/ bmj.298.6676.789, indexed in Pubmed: 2496858.

17. Mannami T, Iso H, Baba S, et al. Japan Public Health Center-Based Prospective Study on Cancer and Cardiovascular Disease Group. Cigarette smoking and risk of stroke and its subtypes among middle-aged Japanese men and women: the JPHC Study Cohort I. Stroke. 2004; 35(6): 1248-1253, doi: 10.1161/01.STR.0000128794.30660.e8, indexed in Pubmed: 15118170.

18. Kuller LH, Ockene JK, Meilahn E, et al. Cigarette smoking and mortality. MRFIT Research Group. Prev Med. 1991; 20(5): 638-654, doi: 10.1016/0091-7435(91)90060-h, indexed in Pubmed: 1758843.

19. Thun MJ, Apicella LF, Henley SJ. Smoking vs other risk factors as the cause of smoking-attributable deaths: confounding in the courtroom. JAMA. 2000; 284(6): 706-712, doi: 10.1001/jama.284.6.706, indexed in Pubmed: 10927778.

20. Towfighi A, Markovic D, Ovbiagele B. Impact of a healthy lifestyle on all-cause and cardiovascular mortality after stroke in the USA. J Neurol Neurosurg Psychiatry. 2012; 83(2): 146-151, doi: 10.1136/jnnp2011-300743, indexed in Pubmed: 22019548.

21. Oza R, Rundell K, Garcellano M. Recurrent Ischemic Stroke: Strategies for Prevention. Am Fam Physician. 2017; 96(7): 436-440, indexed in Pubmed: 29094912.

22. Hardie K, Jamrozik K, Hankey GJ, et al. Trends in five-year survival and risk of recurrent stroke after first-ever stroke in the Perth Community Stroke Study. Cerebrovasc Dis. 2005; 19(3): 179-185, doi: 10.1159/000083253, indexed in Pubmed: 15644631. 
23. Peltonen M, Stegmayr B, Asplund K. Time trends in long-term survival after stroke: the Northern Sweden Multinational Monitoring of Trends and Determinants in Cardiovascular Disease (MONICA) study, 1985-1994. Stroke. 1998; 29(7): 1358-1365, doi: 10.1161/01. str.29.7.1358, indexed in Pubmed: 9660387.

24. Vernino S, Brown RD, Sejvar JJ, et al. Cause-specific mortality after first cerebral infarction: a population-based study. Stroke. 2003; 34(8): 1828-1832, doi: 10.1161/01.STR.0000080534.98416.A0, indexed in Pubmed: 12855836.

25. Brown DL, Lisabeth LD, Roychoudhury C, et al. Recurrent stroke risk is higher than cardiac event risk after initial stroke/transient ischemic attack. Stroke. 2005; 36(6): 1285-1287, doi: 10.1161/01. STR.0000165926.74213.e3, indexed in Pubmed: 15879343.

26. Allen NB, Holford TR, Bracken MB, et al. Geographic variation in one-year recurrent ischemic stroke rates for elderly Medicare beneficiaries in the USA. Neuroepidemiology. 2010; 34(2): 123-129, doi: 10.1159/000274804, indexed in Pubmed: 20068358.

27. Broderick JP, Phillips SJ, O'Fallon WM, et al. Relationship of cardiac disease to stroke occurrence, recurrence, and mortality. Stroke. 1992; 23(9): 1250-1256, doi: 10.1161/01.str.23.9.1250, indexed in Pubmed: 1519279.

28. Gunnoo T, Hasan N, Khan MS, et al. Quantifying the risk of heart disease following acute ischaemic stroke: a meta-analysis of over 50,000 participants. BMJ Open. 2016; 6(1): e009535, doi: 10.1136/ bmjopen-2015-009535, indexed in Pubmed: 26792217.

29. Reeves MJ, Bushnell CD, Howard G, et al. Sex differences in stroke: epidemiology, clinical presentation, medical care, and outcomes. Lancet Neurol. 2008; 7(10): 915-926, doi: 10.1016/S14744422(08)70193-5, indexed in Pubmed: 18722812.

30. Saposnik G, Cote R, Phillips S, et al. Stroke Outcome Research Canada (SORCan) Working Group. Stroke outcome in those over 80: a mul- ticenter cohort study across Canada. Stroke. 2008; 39(8): 23102317, doi: 10.1161/STROKEAHA.107.511402, indexed in Pubmed: 18556583.

31. Persky RW, Turtzo LC, McCullough LD. Stroke in women: disparities and outcomes. Curr Cardiol Rep. 2010; 12(1): 6-13, doi: 10.1007/ s11886-009-0080-2, indexed in Pubmed: 20425178.

32. Tuttolomondo A, Di Raimondo D, Di Sciacca R, et al. Effects of clinical and laboratory variables at admission and of in-hospital treatment with cardiovascular drugs on short term prognosis of ischemic stroke. The GIFA study. Nutr Metab Cardiovasc Dis. 2013; 23(7): 642-649, doi: 10.1016/j.numecd.2012.01.010, indexed in Pubmed: 22502765.

33. Jain M, Jain A, Yerragondu N, et al. The Triglyceride Paradox in Stroke Survivors: A Prospective Study. Neurosci J. 2013; 2013: 870608, doi: 10.1155/2013/870608, indexed in Pubmed: 26317103.

34. Koton S, Schneider ALC, Rosamond WD, et al. Stroke incidence and mortality trends in US communities, 1987 to 2011. JAMA. 2014; 312(3): 259-268, doi: 10.1001/jama.2014.7692, indexed in Pubmed: 25027141.

35. Lu Da, Li P, Zhou Y, et al. Association between serum non-high-density lipoprotein cholesterol and cognitive impairment in patients with acute ischemic stroke. BMC Neurol. 2016; 16(1): 154, doi: 10.1186/ s12883-016-0668-2, indexed in Pubmed: 27561255.

36. Boehme AK, Esenwa C, Elkind MSV. Stroke Risk Factors, Genetics, and Prevention. Circ Res. 2017; 120(3): 472-495, doi: 10.1161/CIRCRESAHA.116.308398, indexed in Pubmed: 28154098.

37. Pol T, Held C, Westerbergh J, et al. Dyslipidemia and Risk of Cardiovascular Events in Patients With Atrial Fibrillation Treated With Oral Anticoagulation Therapy: Insights From the ARISTOTLE (Apixaban for Reduction in Stroke and Other Thromboembolic Events in Atrial Fibrillation) Trial. J Am Heart Assoc. 2018; 7(3), doi: 10.1161/ JAHA.117.007444, indexed in Pubmed: 29419390. 